\section{INTRODUCTORY LECTURE} ON

\section{THE PROGRESS OF OBSTETRICS.}

Dilivered at King's College.

By W. S. PLAYFAIR, M.D., F.R.C.P.,

Professor of Obstetric Medicine in King's College; and Physician for the Diseases of Women and Children to King's College Hospital.

Mr. Principal and Gentlemen,-The honour which the Council of this College has done me in electing me to fill the Chair of Midwifery imposes upon me a responsibility of no light weight. He who takes upon himself to fill the chair once occupied by men so eminent in obstetrics as Robert Ferguson, Arthur Farre, and Priestley-names intimately associated with the progress of the branch of medical science which they taught-cannot but feel much doubt and anxiety as to his powers of worthily following in the footsteps of predecessors so distinguished.

Whether it be granted to me or not to justify the trust which the Council has placed in me, time alone can show ; but one thing, gentlemen, I can confidently assert, and that is, that no one could address you from this place with a more firm conviction of the responsibilities of his situation, or a more anxious desire that the well earned reputation of the chair of midwifery in King's College may not suffer in his hands. It has been well said by one of our most eminent British essayists that "The first essential to success in the art you practise is respect for the art itself." And that qualification, at least, I may claim to possess in a high degree; for I feel a profound conviction, which it will be my endeavour to induce you to share, that there is no department of medicine which is more important, whether as a subject of scientific study full of interest, possessing much ground yet untilled, and promising a rich harvest of results to the zealous cultivator, or as a branch of practice involving questions of the greatest importance not only to the individual, but, in certain aspects, to the community at large, than that which I am privileged to profess before you.

Perhaps I cannot better occupy the hour devoted to our introductory lecture than by attempting to justify these assertions by showing you, very briefly, what great strides in advance have been made since this chair was founded forty odd years ago. Although time will not allow me to attempt anything like an exhaustive account of the progress of midwifery in that period, and will only admit of our glancing in the most cursory way at a few of the chief results gained, still I shall be able to show you that some of the most formidable diseases which hum an flesh is heir to have become amenable to treatment, and that many a woman is now alive in health and strength who, forty years ago, would have inevitably perished, or have dragged on a miserable existence from which death itself would have been a happy release.

This is all the more necessary because midwifery, including in that term the diseases of women and children, has always been in some degree the Cinderella of medicine, and has never yet received, as its votaries believe, that study and recognition to which they consider it to be fairly entitled. Happily signs are not wanting of the advent of the time when, like Cinderella in the fairy tale, its hitherto unappreciated charms will be duly acknowledged. This statement may appear strange to you who, as students of the College, have been accustomed to see our subject placed on a footing of perfect equality with the other great departments of medicine and surgery; and it is a truth which we ought thankfully to acknowledge, that the authorities of this College have always been anxious to promote its study by every means in their power. Still it is one which it would be by no means difficult to prove. The fact that such practitioners as follow what is called pure or consulting practice have naturally come to divide themselves into three great classes of physicians, surgeons, and obstetricians, proves that the importance of the subject has made itself felt. The first two divisions have flourished under the fostering care of venerable and wealthy colleges devoted to their interests, which were founded at a time when midwifery had not emerged from the hands of the ignorant women by whom it was chiefly practised; while the last has been left out in the cold to fight a hard struggle alone, and has only of late years acquired sufficient vigour to claim for itself an equality of position with its more tenderly cared for sisters. If you require a proof that this position has not been acquired without opposition and diffculty, it may be found in the fact that only the other day, when a scheme was broached for uniting the many medical societies of the metropolis into one great body, the framers of the proposal actually placed medicine and surgery together in one branch, while the third great department of practice was made into a subordinate section on a level with other subjects important enough in themselves, but of much more limited extent.

This proposal was happily defeated by the action of the Obstetrical Society, a body which, in its short span of life, has done much to ad. vance the progress of obstetrics; and I mention it here, not by way of complaint, but simply to illustrate the fact that old prejudices and old ideas are not easily relinquished, and in proof of my statement that the subject of our course has not always received the recognition which I believe its importance merits.

The greatest drawback to the teaching of midwifery, however, in the metropolis, is the custom which is prevalent in all our schools of having a short summer course of only three months devoted to its study. Just consider for one moment what obstetrics includes, and you will be convinced of the absolute impossibility of embracing all that comes under that heading in so short a space of time. The obstetrician has to teach the entire anatomy and physiology of the generative organs of the female, including that of the pelvis. He has to consider the great subject of embryology, the signs and symptoms of pregnancy, the description of labour, natural and abnormal, with the operative measures occasionally required. Then he must discuss the important topic of the diseases of the puerperal state, about which every year something fresh has to be learnt. As if this were not more than enough, the teacher of midwifery is responsible for all that the student may learn of the diseases peculiar to women, and of the great topic of child. ren's diseases, each of which is of itself sufficient to give full occupation to a lecturer for a three months' course. The utter futility, therefore, of supposing that all that ought to be taught can be taught in so short a time, is abundantly apparent. The consequence is, that lecturers are perforce obliged to limit themselves to certain portions of the subject only ; and men often leave the schools almost entirely ignorant of such topics as gynæcology and the diseases of children, and have to acquire their knowledge of them - a knowledge essential in practice, as a large proportion of cases coming under their care fall under these heads-at the cost of much labour and anxiety to themselves, if not of serious de. triment to their patients. It is deeply to be regretted that the General Council of Medical Education only last summer put their veto on a proposal to substitute a six months' for a three months' course of mid. wifery, and this in the face of the unanimous recommendation of the metropolitan lecturers on the subject, thereby giving another and a melancholy proof of the existence of the antiquated prejudices already alluded to.

And now, gentlemen, let me attempt to redeem my promise of proving to you that within the last half century obstetric medicine has made advances, which justify us in claiming for it a high position as a branch of study and practice.

In the first place, almost all our knowledge of the mysteries of gene. ration may be said to have been acquired since that time. Men had, indeed, previously speculated on this the most marvellous of nature's works ; but, in the absence of accurate ideas of the physiology of menstruation and conception, nothing but hypothesis, and that often of the wildest kind, was possible. It was only after the discovery of the true structure of the ovum, and of the connection between menstruation and the periodic maturation and expulsion of the ova, that our knowledge of this important subject was placed on a satisfactory footing. Then followed, one after the other, numerous monographs, in which various stages in the process by which the new being is formed and grows were cleared up. The discovery of the change which takes place in the ovum in consequence of the cleavage of the yelk; the proof which Barry and Meissner were able to afford that the spermatozoa actually penetrated the ovule ; the discovery of the wonderful mechanism by means of which the fimbriated extremities of the Fallopian tubes seize and grasp the ovary, and receive the ovule; the demonstration of the precise changes which take place in the Graafian follicle, and of the distinction between true and false corpora lutea, did much to clear up the obscurity in which the early stages of the development of the fœtus had been in. volved. Then we have acquired much new knowledge with regard to the growth and the development of the embryo after it has reached the uterus, and of the changes which take place in that organ to fit it for its reception. Especially curious, from an historical point of view, are the varieties of opinion that have been held with regard to the true nature of the decidua. After the long prevalence of the views enunciated by John Hunter, that this structure was a layer of coagulable lymph thrown out on the inner surface of the uterus - a view universally adopted until within the last few years-we had come to regard the teaching of his illustrious brother William, that the decidua was in fact only the hyper. trophied and altered mucous lining of the uterus itself, as being much 
more near the truth, and had thus gone back to a theory which was considered exploded nearly a century ago. Quite recently, however, the elaborate monographs of Professor Ercolani of Bologna again throw doubt on this subject, and advance the opinion that this structure is formed by a secretion from the uterine glands, affording nutriment to the foetus until the placenta is formed. The same author, if his views stand the test of farther investigation, will have materially modified our opinion as to the structure of the placenta itself, and as to the mode in which it acts as a medium of nutrition to the foetus, by showing that the maternal portion is, in fact, a glandular organ of new formation, secreting a nutritive material to be absorbed by the villi of the chorion. Here also we curiously return to something very like the theory propounded by our own immortal Harvey, who considered the placenta to be a gland having for its object the nourishment of the foetus. With regard to this subject, there still remains a good deal to be worked out; and when we find so accurate an observer as the present teacher of midwifery at Guy's Hospital doubting even the usually received description of the vascular arrangements of the placenta, it is evident that there is still considerable scope for farther observation and research.

It would be impossible to speak of this subject in this place without referring to the share which your last two teachers have had in its progress ; and in the admirable monograph of Dr. Arthur Farre on The Uterus and its Appendages, and in Dr. Priestley's Lectures on the Gravid Uterus, the student will find a mass of information well worthy of his most careful study.

Nor has this department of midwifery been wanting in practical results ; for a good deal has been learnt, and still more remains to be learnt, about the diseases and degenerations to which the placenta and foetus itself are subject. We are now able to trace to them many of the cases of frequent abortion and still-born children, previously inexplicable; and we have even been able sometimes to save the life of the foetus under such circumstances, by artificially inducing labour before the diseased condition of the placenta had rendered intrauterine existence impossible. The dreadful secondary effects of syphilis in connection with pregnancy have been specially worked out; and no long experience in the wards of the hospital will be required to impress strongly on your memory the fact that this loathsome disease often stamps its mark on the innocent wife and children long after all traces of it have been supposed to have disappeared, although its seeds have all along lain latent and unsuspected in the system. Nowhere can you find a more striking and painful illustration of the way in which the sins of the father are visited on his chil. dren, even unto the third and fourth generation.

The experience of all who see much of hospital practice must strongly impress upon them the necessity of using their best endeavours to mitigate the evils of this terrible pest. It is deeply to be regretted that well-meaning, but badly informed and prejudiced, men and women should have succeeded in raising a clamour against an attempt to diminish the prevalence of this disease, which has been conclusively proved not only to lessen the evil, but also to diminish the vice which produces it, and the opposition to which is based on an assumption of injury to the feelings of the unhappy women coming under the province of the act, which every one practically acquainted with the subject must know to be fallacious.

Then, with regard to the process of labour itself, much interesting in. formation has been gained. True, we cannot positively say why the phenomena of labour commence at a certain time, but the microscope has thrown light on the means by which it is brought about; and in the fatty degeneration of the decidua, which causes it to be loosened from the walls of the uterus-a theory first suggested by Sir James Simpson-we most probably have the key to this obstetric puzzle. In our knowledge of the phenomena and mechanism of labour itself great advances have been made. We have now much more accurate ideas than formerly of the force and effect of the labour-pains; and the theory of reflex action enables us to better understand their intimate nature. The mechanism of parturition must ever be a study of interest; and the name of Naegele will always be most intimately associated with all our accurate knowledge of the subject, although the first real step of importance towards a precise idea of the manner in which the head passes through the pelvic canal was made by a British obstetrician, Sir Fielding Ould, who pointed out that the head does not pass through the pelvis in the same direction as that in which it is expelled. The views of Naegelé were universally adopted and taught in this country and on the Continent, and were, indeed, considered to be so firmly established as to leave nothing to be learnt in the matter. It is only within the last few years that they have been shown to be in some important respects inaccurate, and that our teaching in regard to them has to be modified. This advance also we chiefly owe to the researches of our fellow-coun. trymen, especially Leishman and Matthews Duncan.

With regard to the management of labour, the practitioner of to-day stands on a better footing than he of forty years ago. The more accurate notions which we possess with regard to the mechanism of the process, enable us sooner to appreciate the occurrence of any abnormality, and to interfere for the benefit of the patient, or teaches us when we may more wisely leave the case to the unaided powers of nature. We have learnt, also, some valuable lessons from a careful examination of the abdomen externally ; such as the possibility of aiding the force of feeble and ineffective pains by judiciously applied pressure to the uterus. In this plan, indeed, which is, as yet, little known in this country, I feel convinced we have a means of assisting the progress of a labour in which the delay is simply due to the want of sufficient uterine contraction, far safer both to the mother and the child, and far more effective, than the administration of oxytoxic drugs, such as the ergot of rye, in which many place much confidence.

The introduction of anæsthesia will always be looked upon as one of the greatest triumphs of obstetric medicine in the time we are reviewing. At first bitterly opposed, as all such great improvements are, it has long since been recognised, in this country at least, as a perfectly legitimate means of alleviating the pains and perils of childbirth. The difficulty we now find is not to persuade our patients to submit to the use of chloroform, but rather that of keeping its action within due bounds, and of its preventing its interfering with the strength and efficiency of the uterine contractions. Indeed, an anæsthetic agent better suited to ordinary midwifery practice than chloroform, one less likely to do more than we want, is still somewhat of a desideratun. The use of chloral also, as a means of lessening the sufferings of the first stage of labour, when chloroform itself is inadmissible, promises to be a decided addition to our resources, although on this point farther information is yet required.

In the management of the third stage of labour we have also made progress, inasmuch that far more stress is now laid on the necessity of applying firm pressure to the uterus after the expulsion of the child, and thus not only rendering retention of the placenta from uterine inertia a thing almost unknown, but, what is of much more importance, preventing, far more surely than in any other way, the occurrence of post partum hæmorrhage. The parturient woman of to-day also finds her lines cast in more pleasant places than did her mother or grandmother with regard to her management after delivery. Recognising the fact that labour is a natural process, not a disease, we no longer find it necessary to starve our patients for ten days or a fortnight after delivery; and the gruel and slops, in the manufacture of which the Mrs. Gamps of a quarter of a century ago were so proficient, are now happily things of the past. It is no longer necessary for a patient to get up stealthily in the dead of night and steal the bread and butter of the monthly nurse, as the mother of one of my patients assured me had been her custom in her younger days. The gain to the patient, and the increased strength and energy which she feels when her puerperal month is over, are abundantly evi. dent to all who have seen both systems in operation.

In no department of obstetrics have greater advances been made than in the operative procedures which are from time to time necessary in dealing with abnormal cases, not so much in the invention of new operations-though even in this modern science is not wanting-as in the improvement of old ones, and in a better understanding of the indications rendering them necessary. There is no obstetric operation which is not on a better footing than it was forty years ago. Thus, in the operation of turning, often said to have been in its perfection before the invention of the forceps caused it to fall somewhat into disuse, we now know, thanks chiefly to the labours of Dr. Braxton Hicks, how to perform it in suitable cases without introducing the hand into the uterine cavity, by a happy combination of external and internal manipulation, thereby not only increasing the sphere of its applicability, but greatly diminishing the risk both to the mother and to the child. We have learnt, also, that, by a careful examination of the abdomen, it is perfectly possible, in most cases, to ascertain, before labour commences, the position in which the child is lying; and we may be able even to remedy abnormal presentations by altering the position of the fœtus by external manipulation only. Then the range of the operation has been greatly increased, and it is a decided gain to be able to resort to turning in certain cases of contracted brim, where the forceps have failed or are deemed unsuitable, and the deadly perforator is the only alternative. Then, with regard to that greatest of conservative operations, the use of the forceps, the opinion has of late years been steadily gaining ground that instrumental interference should be resorted to in the second stage of labour much more frequently and much sooner than has hitherto been the case. We are coming to see that delay, after the head is in the pelvic cavity, and when we are convinced that the unaided powers of nature are not likely to effect delivery, is not only useless but pernicious, and that by timely interference we lessen the risk to the mother and save the infant's life. The belief is spreading, that the long train of evils which 
we were taught were likely to follow the use of the forceps, and which have hindered many a man from using them when they were decidedly indicated, really arose from pressure on the soft parts and the exhaustion incident to a long labour, and were strictly preventable accidents. It is, indeed, strange to look back on the records of practice in the early part of this century, and see how seldom this most valuable operation was resorted to. When we learn that in so great a school of midwifery as the Rotunda Hospital, between the years 1815 and $182 \mathrm{r}$, out of $2 \mathrm{I}, 867$ deliveries, the forceps was never once used, and between the years 1826 and 1833 , out of 16,654 births, it was only applied twenty-four times, craniotomy having been performed I 8 times in the same number of cases, we cannot but reflect with horror on the num. ber of infants, to say nothing of the mothers, whose lives must have been needlessly sacrificed. That meddlesome midwifery is bad midwifery, is a time-honoured adage, out of which much capital has been made, and it is, no doubt, a true one when applied to the meddling of an uninstructed and ignorant practitioner; but when it is brought forward to regulate the practice of a scientific physician, who knows exactly when to interfere and how to do it, I believe it to be untrue and mischievous. The range of the induction of premature labour has also been much extended ; and we now not only deem it justifiable to bring pregnancy to an end artificially when we know that the pelvis is too narrow to allow a living fotus to pass through it at term, but also in numerous other cases in which either the life of the fotus itself is imperilled at the end of utero-gestation, or when some condition exists which makes the continuance of pregnancy perilous to the mother.

With regard to operations involving the destruction of the foetus, by far the greatest improvement of which we can boast is the diminution of the number of cases in which we are called upon to perform them. When, however, we are unhappily obliged to resort to this most distressing expedient, we have means at our command for performing it with greater ease to ourselves, and greater safety to the patient, than was formerly possible. The cephalotribe was used for many years on the Continent before it was employed in this country, but its manifold advantages have of late gained it a place as a recognised instrument, and year by year it is more resorted to. I do not doubt but before long it will practically supersede, in the majority of cases, the less safe and less manageable craniotomy forceps and crotchet.

With regard to many of the accidents and diseases connected with iabour, our knowledge has been greatly extended. There are few complications more trying to the practitioner, than the various form of hæmorrhage which occur in connection with childbirth. Of that which depends on a faulty position of the placenta, we have a more complete knowledge than we had some years ago. Much of this is due to the somewhat acrimonious discussion which arose after Sir James Simpson wrote his well-known paper on the subject; and his plan of treatment was the precursor of the somewhat analogous methods advocated by Barnes and by Cohen of Hamburgh. The result has been that we have come to understand the particular method of treatment applicable under varying circumstances ; and, what is of importance, we have arrived at a pretty generally admitted conclusion as to the danger of temporising, and as to the advisability of artificially inducing labour as soon as the existence of placenta prævia has been fully determined.

In the treatment of post partum hæmorrhage we have made a decided advance, in learning how to control effectually the severer forms by the injection of astringents into the uterine cavity. With this remedy at our command, and with the still more important means of preventing the accident by promoting contraction of the uterus after delivery carefully attended to, flooding ceases to be the common and terrible accident once so often met with, and so justly dreaded.

Much new information has been acquired within the last forty years from a careful study of the various toxæmic conditions connected with pregnancy, and a new light has been thrown on some of the most formidable accidents and diseases of the puerperal state. There can be no doubt that we have here a wide field of inquiry in which much yet remains to be done, and which promises most valuable results to the zealous student. It is now nearly thirty years since Lever first pointed out the close connection between albuminuria and the convulsions which form so terrible and dangerous a complication of pregnancy. The researches which have been made in connection with this topic, especially those of Frerichs on the uræmic origin of the true puerperal eclampsia, form a valuable chapter in the history of obstetrics. We have not yet, however, arrived at any very positive conclusion as to the precise pathology of the disease, although the recent experiments of Spiegelberg seem to show that Frerichs's theory, that the conversion of the urea circulating in the blood into carbonate of ammonia is the exciting cause of the convulsion, a theory until lately considered to be almost disproved, may yet turn out to be the true one. We are fortunate, however, in having means of treatment of great value at our com. mand, especially the use of chloroform, and, what may prove to be of still more service, the administration of chloral, which seems to have great power in controlling the convulsion.

Then, our knowledge of the pathology of phlegmasia dolens has been greatly increased. We now know that thrombosis is not solely confined to the vessels of the lower extremity, but that the same septic condition of the blood may produce coagulation in the great centres of circulation, and thus cause some of those terribly sudden deaths after delivery, previously inexplicable. We have studied also, to some extent, the changes which take place in the coagula so formed; and we know that portions of them may be detached and carried through the circulatory system to be arrested at some distant point, where they may give rise to important secondary consequences, often suddenly fatal if the point of arrest be in the pulmonary arteries. The whole subject of thrombosis and embolism in connection with pregnancy still requires further elucidation, and promises results of the greatest practical value.

No topic in connection with obstetrics is more important, and about none have more diverse views been advanced, than those fatal forms of disease occurring after delivery which are collectively described under the name of "puerperal fever". Nothing can be more confusing to the student than the attempt to study the diseases classed under this head from the writings of contemporary authorities ; and yet, in spite of all this discrepancy of opinion, much valuable information regarding them has been acquired. Especially important is the knowledge of the highly contagious nature of the malady, and of the painful fact clearly shown by Dr. Braxton Hicks, whose valuable paper should be carefully studied by every practitioner, that many of the worst forms may arise from the contagion of various forms of zymotic disease, too often, alas ! conveyed by the medical attendant himself.

Then we have much knowledge, previously unknown to us, of the autogenetic source of many cases, from the decomposition of retained coagula and secretions, and secondary septic absorption ; and we have learnt a valuable means of treatment in such cases from the intrauterine injection of antiseptic fluids.

We have, also, a mass of information as to the dangers arising from the aggregation of puerperal females in lying-in hospitals, a subject which has given rise to much discussion and difference of opinion; which has, at any rate, had the effect of extending our know. ledge of puerperal disease.

Such are a few only of the recent advances in connection with midwifery ; and I might readily, had time permitted, have told you of many more of equal importance. Enough, however, has surely been said to convince the most sceptical that obstetricians have not been idle, and that they have just reason to feel proud of the progress of the branch of medicine which they cultivate.

Turning to the allied subject of the diseases of women, we find that within the last forty years we have even greater triumphs to boast of. Indeed, gynæcology, as a branch of scientific medicine, may be said to have been almost entirely unknown forty years ago. Let him who doubts this statement take up any work on female disease representing the most advanced knowledge of that date-as, for example, the well known treatise of Sir Charles Mansfield Clarke-and contrast it with any recent work on the same subject, and he will be amazed at the progress which has been made in so short a space of time. Diseases of primary importance and of frequent occurrence were then utterly unknown, and the means of treatment at the command of the practitioner were on a par with his knowledge of the pathology of the uterine organs. The immense advances which have been made coincide with the introduction into practice of accurate methods of physical examination; for, until these were habitually resorted to, the gynæcologist was only working at hap-hazard. We owe, then, a debt of gratitude, which we should not be ashamed to acknowledge, to those who, in the face of much opposition, and in spite of much misrepresentation, rendered familiar to us the use of instruments without which all accurate knowledge of female disease is simply impossible. Not that I trace this progress by any means solely to the use of the speculum, the uterine sound, or the sponge-tent, of themselves, but quite as much to the fact that a more careful and habitual examination of the state of the uterine organs followed and attended their introduction into practice. In former days there was no branch of medicine about which there was more guess-work; while now it is the good fortune of the gynæeologist to be able to say with truth that there is no department of medicine or surgery, with the exception, perhaps, of diseases of the eye, in which a more precise and accurate knowledge of the actual condition of the organs affected is attainable.

As nearly everything in so wide a subject is the growth of the last forty years, it would be simply out of the question to attempt, in the few minutes that remain to us, even a bare enumeration of the ad. 
vances that have been made. It is impossible, however, not to refer to one or two of the most striking. The steady progress of ovariotomy to its present place as a legitimate and successful operation, is one which we cannot pass over in silence. British practitioners may justly claim a large share in this success; for, although the operation was first performed in America, the labours of British surgeons have been chiefly instrumental in extending its employment, so that it is now habitually performed in nearly every civilised country. When we reflect that from 70 to 80 per cent. of those operated on recover, who would otherwise have inevitably perished, since it is calculated that 90 per cent. of the cases left to themselves die within two years, we can readily understand how great an addition to the resources of surgery ovariotomy has proved itself to be. In the treatment of the other great class of tumours-the fibroid tumours of the uterus-so much has not been done; nor can it be expected. We have learnt, however, that Nature in some rare cases does for us what Art is unable to accomplish; and it is not unreasonable to hope that a careful study of the means by which so strange and mysterious an occurrence as the spontaneous absorption of such growths is effected, may in time enable us to hit upon some method of promoting it artificially. The surgeon has also devised some plans of successfully dealing with cases in which hæmorrhage is imperilling the life of the patient, and further progress in this direction may be confidently anticipated.

To our American brethren we owe a debt of gratitude for showing us how to cure successfully one of the most distressing, and formerly one of the most irremediable, of human ailments-viz., vesico-vaginal fistula. It is almost impossible for us to realise the life-long misery of the sufferers from this dreadful accident, whose existence must have been a burden to themselves. No chapter in the history of our art is more curious than that which relates the unceasing efforts which surgeons have made to cure this affection, and the disheartening failures which always attended their operations. Now, happily, vesico-vaginal fistula is no longer the opprobrium chirurgia, and we can almost certainly promise the sufferer a speedy and a lasting cure.

The inflammatory and congestive affections of the uterus itself have attracted much attention; and in the judicious application of intrauterine medication to suitable cases-a method of treatment as yet but little known in this country - we have a means at our command of effectually dealing with some most intractable affections. Allied to this topic is one which has been a fruitful theme of discussion-viz., the flexions and displacements to which the uterus is subject, which some look upon as the secondary consequence of certain inflammatory affections of that organ, and others as a primary and most important condition, to be remedied chiefly by mechanical contrivances. Probably there is some truth in both views; and here, as elsewhere, a too onesided way of looking at the question is likely to be erroneous. Then there is an entirely new class of most important affections, which have been chiefly studied by French physicians, about which we are year by year gaining fresh knowledge : these consist chiefly of various inflammatory affections in the neighbourhood of the uterus, either of the pelvic cellular tissue or of the peritoneum ; and of effusions of blood into and about the same structures. A knowledge of them, and of their secondary results, enables us to explain many cases which must previously have baffled the most experienced physicians.

The diseases of children form an important and long neglected branch of medicine, which is generally supposed to come within the province of the obstetrician. Considering the great importance of the subject, and the immense mortality among the young, it is really surprising that so little has been done to increase our knowledge of infantile disease. The reason is, no doubt, partly that the obstetrician found it impossible to overtake this topic in the short space of time devoted to his lectures, but chiefly from the want of children's wards or hospitals in which the diseases of the young could be collectively studied. Until, indeed, the Children's Hospital in Ormond Street was founded, little or nothing had been done to meet this great want, and many a little sufferer must have passed away whose life might in these days have been preserved. Much of the increased attention paid to infantile disease in this country we owe to the labours of the eminent physician who took so great a part in founding that hospital, and whose elegant and classical treatise on the diseases of children will always cause his name to be honourably associated with the progress of his favourite study.

Of late years the profession has awakened to the necessity of affording the student the opportunity of making himself practically acquainted with infantile disease ; and in almost all our large hospitals, children's wards have been established, our own having been one of the first to set the example. The result has been a decided advance in our knowledge of the subject, which is year by year increasing. It will now certainly be your own fault if you commence practice ignorant of the peculiarities of disease in those who will form a large proportion of your patients.

And now, gentlemen, I must of necessity bring this imperfect review of the progress of obstetric medicine to a close. It is impossible to refer to a tithe of the subjects which crowd on us for remark; but, although much has been omitted, I feel sure that enough has been said to convince you that such advances have been made as will challenge comparison with those of any other branch of medicine or surgery. Do not, however, suppose that we have by any means exhausted the mine. As long as it is woman's doom to bring forth children in sorrow, so long will it be the proud privilege of our art to alleviate her sufferings; and year by year we may hope to gain fresh triumphs in a field in which so many honours have been reaped in so short a space of time.

Permit me one word of warning ere we part. It has sometimes been objected to obstetric practice that it is much open to abuse, and that those who follow it are peculiarly liable to temptation to magnify the ailments of their patients, and to make capital out of imaginary dis. orders. That there are peculiarities about this branch of medicine which make it easy for the charlatan to ply his base arts can hardly be denied ; that it has been so abused, to any great extent, I hope and believe is not the case. But if anything will protect obstetricians from misconception and misrepresentation, it is a high tone of feeling with regard to their responsibilities; let me entreat you to cultivate this to the utmost, never to forget how great is the confidence placed in you, and how scrupulously careful of the welfare of your patient you ought to be in return.

"To thine own self be true, And it must follow, as the night the day,"
Thou canst not then be false to any man."

\section{ABSTRACT OF LECTURES}

ON

\section{PRIMORDIAL AND OTHER CAUSES OF DISPLACE- MENTS OF THE UTERUS; WITH THEIR DIAGNOSIS AND TREATMENT.}

BY PROTHEROE SMITH, M.D., Senior Physician to the Hospital for Women, etc.

\section{LECTURE I.}

[HAVING referred to certain peculiarities in the supply of nerves and vessels to the different parts of the generative organs as indications of their several physiological import, and as also explaining their various pathological changes, the lecturer, after some general and introductory remarks, and after referring to the striking analogies offered by comparative anatomy, spoke of the anatomical condition of the uterus in its development. In describing the successive stages in the development of the uterus and its appendages, Dr. Protheroe Smith pointed out those peculiarities of form and relationship to contiguous parts which, when arrested or abnormally developed, often laid the founda. tion of congenital imperfection. After this, he said :]

The etiology of uterine flexions has for a long while remained obscure and inexplicable, notwithstanding the various theories which have been suggested. I am desirous to show that, although displacements of the organ may take place bodily at any time, actual flexion upon itself may pre-exist at birth, or (in the form of atrophy or otherwise) may appear at certain periods of the evolution of the genital organs, or at the time of such physiological modifications of the uterus as occur at menstruation, utero-gestation, parturition, and involution ; and that in all other instances, pathological alterations of structure form the predisposing cause of such cases as are supposed to be produced spontaneously. This distinction, as it affects the subject of inflexions, may not always be obvious, since the predisposing cause, after a time, may have disappeared altogether, whilst the deformity it has created exists alone, or it may give rise to other complications, of which I shall speak hereafter.

It is worthy of remark, that the organs of generation have a mode of development sui generis, that they present, in an embryonic state, a series of successive transformations, which gradually so assume the characteristics of animal life as to declare the sex as well as the species. After the sex becomes evident, there is an arrest in the process ; and even after birth, the genital organs, though arrived at their last evolution, remain rudimentary, until approaching puberty excites a further nutritive effort, which completes their development, and forms the woman with a rapidity and excitement which often gives the process a pathological aspect; and this, too, may be said also of the full 